\title{
A Standard Mammography Unit - Standard 3D Ultrasound Probe Fusion Prototype: First Results
}

\author{
Fusionsprototyp aus einem Standard-Mammografiegerät \\ und einem Standard-3-D-Ultraschallkopf: erste Ergebnisse
}

Authors

Rüdiger Schulz-Wendtland ${ }^{1}$ *, Sebastian M. Jud ${ }^{2 *}$, Peter A. Fasching ${ }^{2}$, Arndt Hartmann ${ }^{3}$, Marcus Radicke ${ }^{4}$, Claudia Rauh ${ }^{2}$, Michael Uder ${ }^{1}$, Marius Wunderle ${ }^{2}$, Paul Gass ${ }^{2}$, Hanna Langemann², Matthias W. Beckmann², Julius Emons ${ }^{2}$

\section{Affiliations}

1 Institute of Diagnostic Radiology, University Hospital Erlangen, Erlangen, Germany

2 Department of Gynecology and Obstetrics, University Hospital Erlangen, Comprehensive Cancer Center Erlangen-EMN, Friedrich-Alexander University ErlangenNuremberg, Erlangen, Germany

3 Institute of Pathology, University Hospital Erlangen, Comprehensive Cancer Center Erlangen-EMN, FriedrichAlexander University Erlangen-Nuremberg, Erlangen, Germany

4 Siemens Healthcare GmbH, Erlangen, Germany

Key words

mammography, breast ultrasound, complementary breast diagnostics

Schlüsselwörter

Mammografie, Brustultraschall, komplementäre

Mammadiagnostik

received 22.3.2017

revised 26.3.2017

accepted 27.3.2017

Bibliography

DOI https://doi.org/10.1055/s-0043-107034

Published online 27.4. 2017 | Geburtsh Frauenheilk 2017; 77: 679-685 @ Georg Thieme Verlag KG Stuttgart · New York | ISSN 0016-5751

Correspondence

Rüdiger Schulz-Wendtland, M.D.

Institute of Diagnostic Radiology, University Hospital Erlangen Universitätsstraße 21-23, 91054 Erlangen, Germany

ruediger.schulz-wendtland@uk-erlangen.de

https://doi.org/10.1055/s-0043-107034

\section{ABSTRACT}

Aim The combination of different imaging modalities through the use of fusion devices promises significant diagnostic improvement for breast pathology. The aim of this study was to evaluate image quality and clinical feasibility of a prototype fusion device (fusion prototype) constructed from a standard tomosynthesis mammography unit and a standard 3D ultrasound probe using a new method of breast compression.

Materials and Methods Imaging was performed on 5 mastectomy specimens from patients with confirmed DCIS or invasive carcinoma (BI-RADS ${ }^{\mathrm{TM}} 6$ ). For the preclinical fusion prototype an ABVS system ultrasound probe from an Acuson S2000 was integrated into a MAMMOMAT Inspiration (both Siemens Healthcare Ltd) and, with the aid of a newly developed compression plate, digital mammogram and automated 3D ultrasound images were obtained.

Results The quality of digital mammogram images produced by the fusion prototype was comparable to those produced using conventional compression. The newly developed compression plate did not influence the applied $x$-ray dose. The method was not more labour intensive or time-consuming than conventional mammography. From the technical perspective, fusion of the two modalities was achievable.

Conclusion In this study, using only a few mastectomy specimens, the fusion of an automated 3D ultrasound machine with a standard mammography unit delivered images of comparable quality to conventional mammography. The device allows simultaneous ultrasound - the second important imaging modality in complementary breast diagnostics - without increasing examination time or requiring additional staff.

\section{ZUSAMMENFASSUNG}

Ziel Die Kombination verschiedener bildgebender Verfahren in Fusionsmaschinen verspricht, eine deutliche Verbesserung der Brustdiagnostik mit sich zu bringen. Hier wollen wir die Bildqualität und die klinische Anwendbarkeit eines Fusionsprototypen aus einem Standard-Mammografie/Tomosynthese-Gerät und einem Standard-3-D-Ultraschallkopf unter Zuhilfenahme einer neuen Methode der Brustkomprimierung evaluieren. 
Material und Methoden Für die Untersuchung an 5 Mastektomiepräparaten von Patientinnen mit histologisch gesichertem DCIS oder invasivem Mammakarzinom (BI-RADS'M 6) wurde an einem präklinischen Fusionsprototyp ein Ultraschallkopf eines ABVS-Systems aus einem Acuson S2000 in einen MAMMOMAT Inspiration (beide Siemens Healthcare $\mathrm{GmbH}$ ) unter Zuhilfenahme einer neu entwickelten Kompressionsplatte integriert und digitale Mammografien und 3-DBilder per automatisiertem Ultraschall aufgenommen.

Ergebnisse Die durch den Fusionsprototyp aufgenommenen digitalen Mammografien sind von vergleichbarer Qualität wie unter herkömmlicher Kompression entstandene Aufnahmen. Die neu entwickelte Kompressionsplatte hat keinen Einfluss auf die applizierte Röntgendosis. Der personelle und zeitliche Aufwand für die Mammografie unterscheidet sich nicht zur herkömmlichen Mammografie. Die Fusion aus Mammografie und Ultraschall lässt sich technisch umsetzen.

Schlussfolgerung Die Fusion eines automatisierten 3-D-Ultraschallgeräts mit einem Standard-Mammografiegerät liefert an unseren wenigen Mastektomiepräparaten Mammografieaufnahmen von vergleichbarer Qualität. Darüber hinaus ermöglicht das Gerät den simultanen Ultraschall als 2. Bildmodalität der komplementären Mammadiagnostik ohne einen signifikanten Zeit- und zusätzlichen Untersucheraufwand.

\section{Introduction}

Multimodal imaging continues to be standard for the diagnosis of malignant tumours of the breast. There are however various problems, discussion points and challenges regarding the different imaging modalities (mammography/tomosynthesis, ultrasound and MRI) in their individual areas of clinical application. In the screening domain, where mammography is used exclusively [1], the high diagnosis rate of non-lethal tumours (overdiagnosis) is cited $[2,3]$. And tumours that are missed on mammogram alone, e.g. due to high mammographic density, are also a problem (underdiagnosis) $[4,5]$. In the diagnostic domain, where complementary breast imaging with both ultrasound and mammography is standard [6], spatial mapping requires further optimisation.

Current strategies to optimise diagnostic imaging include improving the quality of the individual modalities, integrating computer-assisted evaluation [7], focusing on three-dimensional modalities [8] and combining the different modalities (fusion) $[9,10]$. Since the development of three-dimensional mammography (tomosynthesis) and ultrasound (automated breast ultrasound) interest has especially focused on fusion devices, as the characterisation of breast lesions can be difficult when these modalities are used independently. The error rate on correlation between lesions detected on mammogram compared to hand-held ultrasound is around $10 \%$ [11]. The combination of modalities in a single continuous examination of the immobilised breast could help to reduce these problems.

The fusion approach to improve breast diagnostic imaging whereby multiple imaging modalities such as mammography, breast ultrasound, MRI and tomosynthesis are combined - the strengths of the one compensating for the weaknesses of the other - is not new [10,12-14]. Combining modalities, however, presents new challenges such as how to perform multiple imaging procedures on the compressed breast in series or simultaneously without changing its position. This is essential for precise localisation of regions of interest (ROI). Combined imaging is currently not yet part of routine clinical practice due to an unfavourable cost-benefit ratio and a lack of technical feasibility [10].
In contrast to previous studies in which principally analogue images were acquired $[12,15,16]$ this study was based on digital mammography and 3D ultrasound examination.

The aim was to validate a functional fusion prototype using a small number of mastectomy specimens.

\section{Methods}

\section{Development of a novel gauze compression device}

A compression device for breast immobilisation is an essential requirement for a combination unit required to perform both ultrasound and mammography/tomosynthesis in a single examination session. The mammogram is performed according to radiological standards [17] as stipulated in the mammography screening guidelines $[6,18]$. X-rays and ultrasound waves should not be impeded and the quality of images not compromised. Breast coverage should be as complete as possible for both the mammogram and ultrasound examination components. A newly developed compression device consisting of an elastic gauze mounted onto a frame provided the required breast compression (up to 100 Newton [N] [19]) (॰ Fig. 1).

\section{Integration into the mammography unit}

The MAMMOMAT Inspiration served as the basic unit. Ultrasound imaging was carried out by a probe from an Acuson S2000 ABVS machine (both Siemens Healthcare Ltd). The ultrasound probegauze unit is flanged-mounted to the mammography unit via a horizontal lowerable holder instead of the standard compression plate ( $\triangleright$ Fig. 2). The entire unit can hereby be moved up or down enabling variation of the compression force applied to the breast. The prototype described here is a research tool and is not commercially available.

\section{Specimens}

The mastectomy specimens were obtained during the iMODE-B study (Imaging and Molecular Detection study Breast). All the patients were fully informed and gave written consent to study inclusion. The study was approved by the medical faculty ethics commission of the Friedrich-Alexander University, Erlangen-Nürnberg. 
Fusion prototype imaging was performed on unfixed abladates in the Erlangen University Hospital radiology institute, department of gynaecological radiology. Thereafter the abladates were passed on to the hospital's pathology institute for evaluation of resection margins and histological analysis.

\section{Imaging procedure}

Each mastectomy specimen was $x$-rayed twice, first using the standard compression plate and then the newly developed compression gauze. For the latter the breast is compressed to the required thickness with up to $100 \mathrm{~N}$ by the taut elastic gauze fixed to the underside of the compression frame. This is equivalent to the same pressure applied during conventional mammography [19]. The compression applied by the gauze can be adjusted according to the individual breast shape allowing the pressure to be evenly distributed. A craniocaudal (CC) mammogram is performed with the mammography unit using a standard protocol. During $x$-ray imaging the ultrasound probe remains outside the field of radiation at the edge of the compression plate. Ultrasound imaging then follows without any repositioning of the already compressed breast. The probe frequency can be adjusted to suit individual circumstances. After completion of the mammogram conventional ultrasound gel is applied to the gauze ahead of the probe. The probe, attached to a threaded rod, then automatically travels out from right to left over the compressed breast. The ultrasound machine's (Siemens Acuson S2000 ABVS) standard software is used for $3 \mathrm{D}$ image reconstruction. Finally the gauze is replaced by the conventional compression plate and an additional image obtained for comparison. The gauze was replaced after each examination for hygienic reasons.

\section{Quality evaluation}

Each pair of images (gauze compression and conventional compression plate) was assessed independently in randomised order by two radiologists who were blinded to patient details. Image pairs were evaluated for quality by internal comparison. In addition they were assessed for the detection of microcalcification, macrocalcification and masses, all of which are regarded as possible correlates of malignant or premalignant lesions [20]. The case series analysis was purely descriptive at the level of the depiction of findings in each specimen. The image pairs are shown in - Fig. 3.

\section{Results}

Combined imaging with mammography and automated ultrasound was successfully performed on all 5 mastectomy specimens.

\section{Patient characteristics}

Patient characteristics are listed in $>$ Table 1. Various clinical scenarios were chosen in order to provide as comprehensive an assessment of image quality as possible. Included were: a case of a previously operated breast (patient 1); a case of DCIS (patient 2); a case of breast carcinoma following neoadjuvant chemotherapy

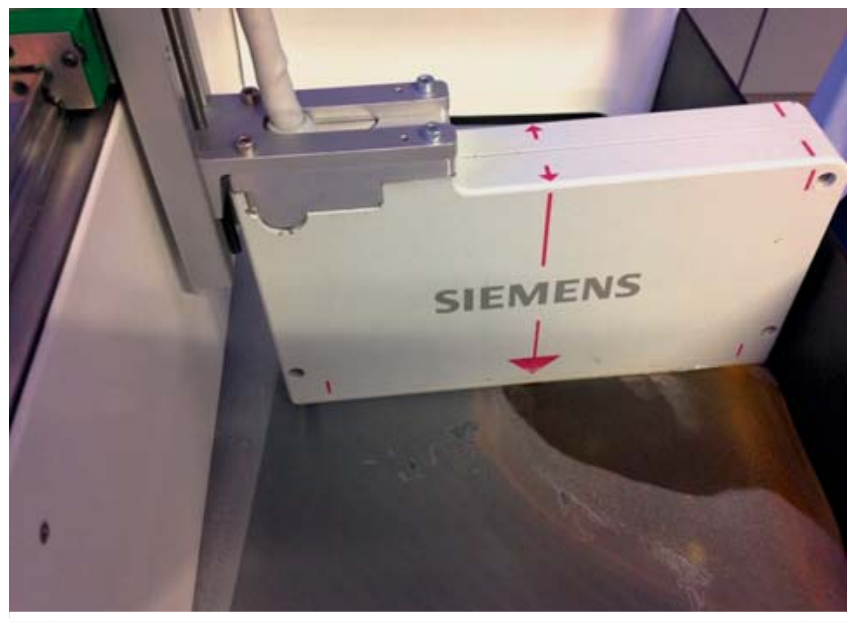

- Fig. 1 The ultrasound probe - taken from the ABVS ultrasound machine - moves over the compressed (elastic gauze) breast phantom.

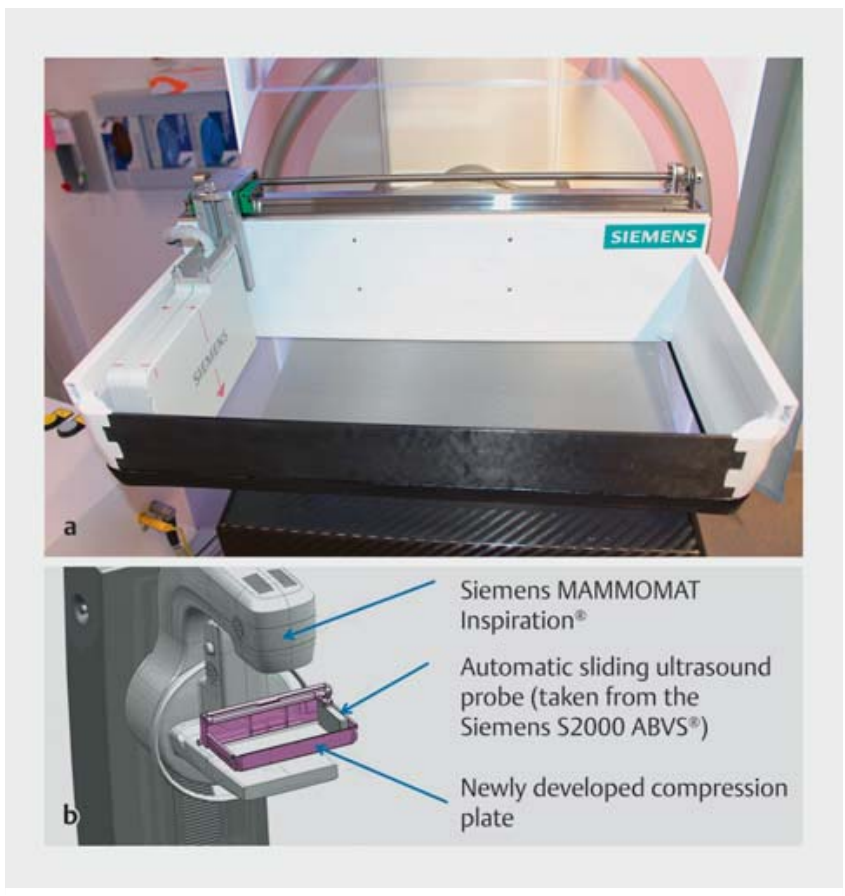

- Fig. 2 a The illustration shows the prototype attached to the Siemens MAMMOMAT Inspiration. The automatic, adjustable ultrasound probe taken from a Siemens S2000 ABVS system is seen mounted on a threaded rod (left in picture) up against the transparent gauze that provides breast compression. b Schematic representation of the integrated mobile ultrasound probe-gauze unit. 


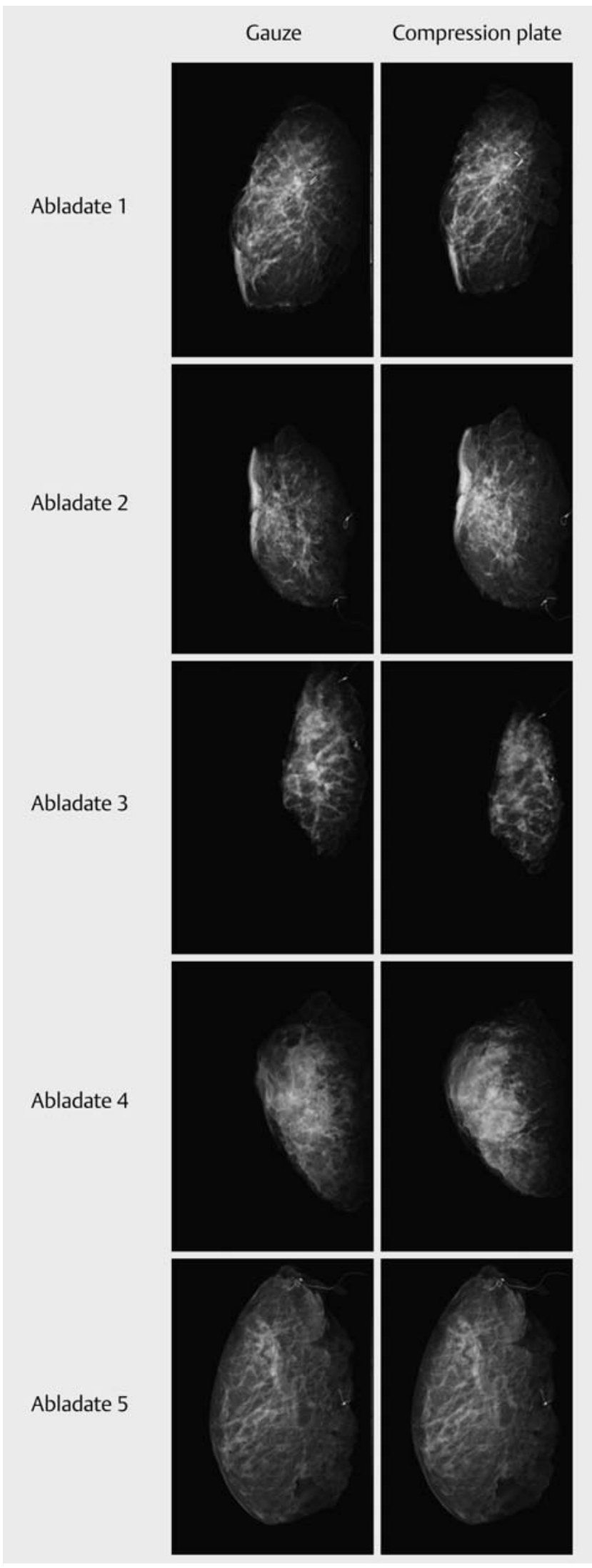

- Fig. 3 The illustration shows CC images of an abladate; on the right with conventional compression (mammography unit), on the left with compression gauze. (patient 4); and one case each of unifocal (patient 3) and multifocal (patient 5) breast carcinoma.

\section{Evaluation of feasibility}

Positioning and compression of the breast, the mammogram and ultrasound examinations were all unproblematic. Compression and mammography were not more time-consuming or labour intensive than conventional mammography. The required pressure for breast compression was achieved without difficulty. The pressure actually needed was significantly below the maximum possible pressure in 4 of the 5 cases ( $\vee$ Table 1 ). Automated ultrasound examination and changing of the compression gauze were also unproblematic.

\section{Evaluation of the compression procedure}

Using the gauze was unproblematic, both for breast compression and specimen alignment. The degree of compression necessary for a high quality mammogram was achieved in every case. The actually required compression force for each individual case did not differ significantly between the two methods (see $>$ Table 1 ).

\section{Image quality when using compression gauze compared to conventional compression plate}

The quality of the two imaging methods was found to be comparable using the above mentioned comparison procedure. On comparison of mastectomy specimen image pairs one radiologist considered them identical in all 5 cases. In 2 cases the second radiologist rated the quality slightly better for the mammograms with conventional compression; the remaining 3 cases received equal ratings. The ability to detect microcalcification, macrocalcification and masses was identical for the two compression methods. Results are summarised in $>$ Tables 2 and $\mathbf{3}$.

\section{Evaluation of ultrasound images}

Automated ultrasound of the compressed breast could be performed quickly (approx. $70 \mathrm{sec}$ ) through the gauze. When compared to the mammogram ultrasound provided almost complete coverage of the specimen. A narrow band of tissue including the nipple region and skin was not covered by the ultrasound examination due to the compressed breast's convex form. Reconstruction of a 3D picture from the individual images was possible. - Fig. 4 shows the mammogram (right), the sagittal automated ultrasound image (below) and the 3D reconstruction (left).

\section{Discussion}

This fusion prototype consisting of a mammography unit and a standard 3D ultrasound probe enables the combination of mammography and ultrasound examination by a single machine. Both imaging modalities are performed on the immobilised breast during one examination procedure without the position or form of the breast being changed.

Advantages are that the patient does not have to change position for the two images, both images are performed practically at the same time, and that the breast remains in an identically compressed condition for both images. The problems of position 
- Table 1 Patient characteristics. Clinical data and the compression force in Newton required for an adequate mammogram are listed for each of the 5 patients.

\begin{tabular}{|l|l|l|l|l|l|}
\hline Patients & Age (years) & PT & $\begin{array}{l}\text { Weight of abladate } \\
\mathbf{( g )}\end{array}$ & $\begin{array}{l}\text { Size of findings } \\
\text { (cm) }\end{array}$ & $\begin{array}{l}\text { Compression force (N) } \\
\text { plate/gauze }\end{array}$ \\
\hline 1 & 58 & pTis & 551 & - & $97.6 / 88.8$ \\
\hline 2 & 71 & pTis & 372.4 & 8.9 & $48.2 / 52.2$ \\
\hline 3 & 50 & pT1c & 249.5 & 1.6 & $26.7 / 32.5$ \\
\hline 4 & ypT2 & 408 & 2.5 & $39.7 / 32.8$ \\
\hline 5 & 50 & pT2m & 767 & 4.6 & $19.4 / 21.9$ \\
\hline
\end{tabular}

- Table 2 Direct comparison of images with compression gauze and compression plate. Each letter represents a rating by one of the radiologists.

\begin{tabular}{|c|c|c|c|c|c|}
\hline Patient & 1 & 2 & 3 & 4 & 5 \\
\hline 1 & & & A & B & \\
\hline 2 & & & $\mathrm{~A} / \mathrm{B}$ & & \\
\hline 3 & & & $\mathrm{~A} / \mathrm{B}$ & & \\
\hline 4 & & & A & B & \\
\hline 5 & & & $\mathrm{~A} / \mathrm{B}$ & & \\
\hline
\end{tabular}

- Table 3 Rating of compression methods (compression plate and compression gauze) for ability to detect microcalcification, macrocalcification and mass lesions. Each letter represents a rating by one of the radiologists.

\begin{tabular}{|l|l|l|l|}
\hline Patient & $\begin{array}{l}\text { Tumour visible } \\
\text { (yes/no) }\end{array}$ & $\begin{array}{l}\text { Microcalcification visible } \\
\text { (yes/no) }\end{array}$ & $\begin{array}{l}\text { Macrocalcification visible } \\
\text { (yes/no) }\end{array}$ \\
\hline 1: Gauze & n. a. & A/B & \\
\hline 1: Compression plate & & $\mathrm{A} / \mathrm{B}$ & $\mathrm{A} / \mathrm{B}$ \\
\hline 2: Gauze & $\mathrm{A} / \mathrm{B}$ & $\mathrm{A} / \mathrm{B}$ & $\mathrm{A} / \mathrm{B}$ \\
\hline 2: Compression plate & $\mathrm{A} / \mathrm{B}$ & $\mathrm{A} / \mathrm{B}$ & \\
\hline 3: Gauze & $\mathrm{A} / \mathrm{B}$ & $\mathrm{A} / \mathrm{B}$ & \\
\hline 3: Compression plate & $\mathrm{A} / \mathrm{B}$ & $\mathrm{A} / \mathrm{B}$ & $\mathrm{A} / \mathrm{B}$ \\
\hline 4: Gauze & $\mathrm{A} / \mathrm{B}$ & $\mathrm{A} / \mathrm{B}$ & $\mathrm{X} / \mathrm{X}$ \\
\hline 4: Compression plate & $\mathrm{A} / \mathrm{B}$ & $\mathrm{A} / \mathrm{B}$ & \\
\hline 5: Gauze & $\mathrm{A} / \mathrm{B}$ & $\mathrm{A} / \mathrm{B}$ & \\
\hline 5: Compression plate & $\mathrm{A} / \mathrm{B}$ & $\mathrm{A} / \mathrm{B}$ & \\
\hline A: selection radiologist 1, B: selection radiologist 2 & & \\
\hline
\end{tabular}

change and biological factors such as cyclical fibrocystic changes are therefore much less significant [21]. This has improved suboptimal correlation of findings between the individual modalities [11].

As has been shown in other studies with similar forms of compression [13] the compression gauze did not reduce the quality of mastectomy specimen images. This suggests that the image qual- ity of mammograms performed on patients using this method will be just as good, so that appropriate clinical studies can now be planned. This prototype allows automated ultrasound imaging and $3 \mathrm{D}$ reconstruction. The extent of breast coverage however does not yet allow detailed assessment of the nipple or subcutaneous regions, a problem also experienced by other study groups [21]. Current research is focusing on optimising ultrasound cover- 

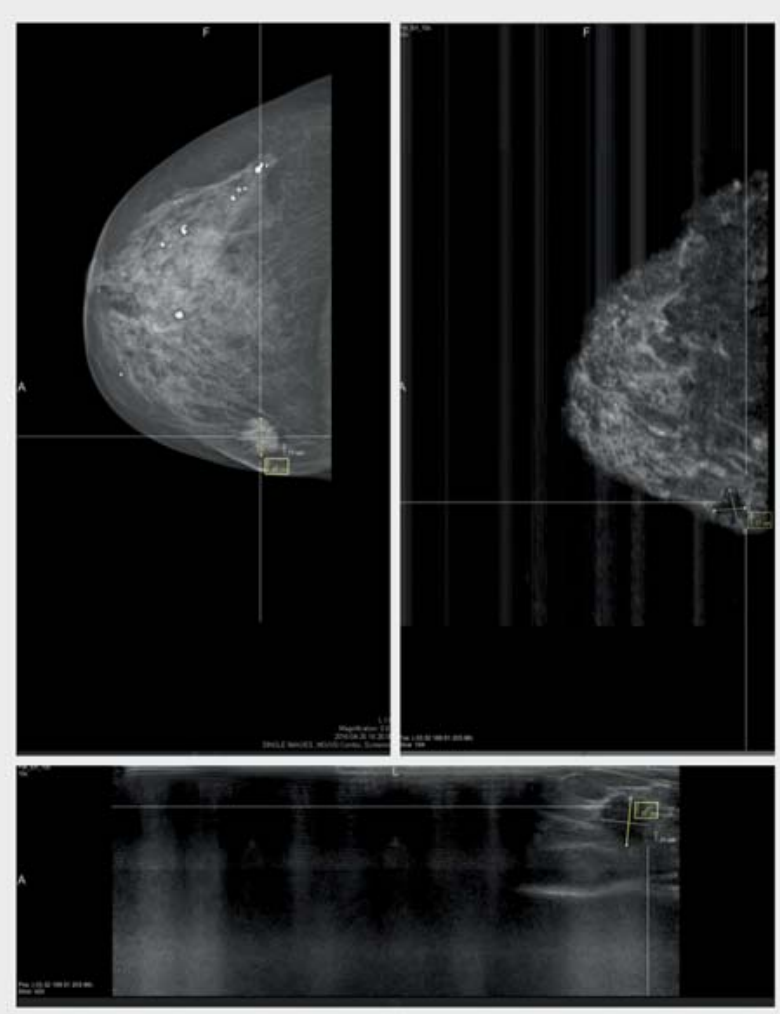

- Fig. 4 The illustration shows the mammogram of a patient with a CT2 invasive breast carcinoma, right; below, the ROI from the practically simultaneously performed ultrasound examination; left, 3D breast reconstruction of the ROI.

age of the whole breast. Although we did not specifically evaluate the quality of $3 \mathrm{D}$ ultrasound in this study, a strong impression was gained that - apart from coverage of the above mentioned regions - there were no qualitative deficits.

This study has shown that the fusion of these two modalities is also possible with digital technology. Although the strength of a study with only five specimens is low, the automatic correlation of lesion localisation between the two modalities appeared to be very accurate.

These findings are still of limited significance, firstly due to the low number of examined specimens and secondly due to a lack of implementation in routine clinical practice. A definitive evaluation of 3D ultrasound image quality is also still lacking.

Nevertheless these results should prompt further study and improvement of this technology. Future studies should assess the feasibility of the method with respect to patient pain perception, duration of examination and image analysability. Ultrasound coverage of the breast through modification of the ultrasound probe and gauze, as well as automated spatial mapping should be further studied and optimised. Lastly, the learning curve associated with this technology also requires study.

\section{Conclusion}

The fusion of an automated 3D ultrasound machine with a standard mammography unit delivers mammogram images of comparable quality to conventional mammograms as demonstrated on a few mastectomy specimens. In addition, this prototype allows simultaneous ultrasound - a second imaging modality as part of complementary breast diagnostics - with no significant increase in examination time or personel requirements.

\section{Conflict of Interest}

The authors declare that they have no conflict of interest.

\section{References}

[1] Welch HG. Screening mammography-a long run for a short slide. N Engl J Med 2010; 363: 1276-1278

[2] Puliti D, Duffy SW, Miccinesi G et al. Overdiagnosis in mammographic screening for breast cancer in Europe: a literature review. J Med Screen 2012; 19 (Suppl. 1): 42-56

[3] Jørgensen KJ, Keen JD, Gøtzsche PC. Is mammographic screening justifiable considering its substantial overdiagnosis rate and minor effect on mortality? Radiology 2011; 260: 621-627

[4] Boyd NF, Huszti E, Melnichouk O et al. Mammographic features associated with interval breast cancers in screening programs. Breast Cancer Res 2014; 16: 417

[5] Weigel S, Heindel W, Heidrich J et al. Digital mammography screening: sensitivity of the programme dependent on breast density. Eur Radiol 2016; DOI: $10.1007 /$ s00330-016-4636-4

[6] Leitlinienprogramm Onkologie. Interdisziplinäre S3-Leitlinie für die Diagnostik, Therapie und Nachsorge des Mammakarzinoms Langversion 3.0. Update, 2012. Online: http://www.awmf.org/uploads/tx_szleitlinien/ 032-045OL_I_S3_Brustkrebs_Mammakarzinom_Diagnostik_Therapie_ Nachsorge_2012-07.pdf; last access: 02.02.2017

[7] Dromain C, Boyer B, Ferré R et al. Computed-aided diagnosis (CAD) in the detection of breast cancer. Eur J Radiol 2013; 82: 417-423

[8] Ciatto S, Houssami N, Bernardi D et al. Integration of 3D digital mammography with tomosynthesis for population breast-cancer screening (STORM): a prospective comparison study. Lancet Oncol 2013; 14: 583-589

[9] Hopp T, Baltzer P, Dietzel M et al. 2D/3D image fusion of X-ray mammograms with breast MRI: visualizing dynamic contrast enhancement in mammograms. Int J Comput Assist Radiol Surg 2012; 7: 339-348

[10] Schulz-Wendtland R, Wittenberg T, Michel T et al. [Future of mammography-based imaging]. Radiologe 2014; 54: 217-223

[11] Conway WF, Hayes CW, Brewer WH. Occult breast masses: use of a mammographic localizing grid for US evaluation. Radiology 1991; 181 : 143-146

[12] Richter K, Prihoda H, Heywang-Köbrunner SH et al. Description and first clinical use of a new system for combined mammography and automated clinical amplitude velocity reconstructive imaging breast sonography. Invest Radiol 1997; 32: 19-28

[13] Booi RC, Krücker JF, Goodsitt MM et al. Evaluating thin compression paddles for mammographically compatible ultrasound. Ultrasound Med Biol 2007; 33: 472-482

[14] Schulz-Wendtland R, Bani M, Lux MP et al. Pilot study on the detection of simulated lesions using a 2D and 3D digital full-field mammography system with a newly developed high resolution detector based on two shifts of a-Se. Geburtsh Frauenheilk 2012; 72: 408-411 
[15] Schütze B, Marx C, Fleck M et al. Diagnostic evaluation of sonographically visualized breast lesions by using a new clinical amplitude/velocity reference imaging technique (CARI sonography). Invest Radiol 1998; 33: 341-347

[16] Li B, Thibault JB, Hall AL. Combining X-ray and ultrasound imaging for enhanced mammography. US Patent 7831015 B2, 2010

[17] Schulz-Wendtland R, Fuchsjäger M, Wacker T et al. Digital mammography: an update. Eur J Radiol 2009; 72: 258-265

[18] Mühlhauser I. Screening auf Brustkrebs/Mammografie-Screening. DZO 2013; 45: 80-85
[19] Poulos A, McLean D, Rickard M et al. Breast compression in mammography: how much is enough? Australas Radiol 2003; 47: 121-126

[20] Morgan MP, Cooke MM, McCarthy GM. Microcalcifications associated with breast cancer: an epiphenomenon or biologically significant feature of selected tumors? J Mammary Gland Biol Neoplasia 2005; 10: 181-187

[21] Kapur A, Carson PL, Eberhard J et al. Combination of digital mammography with semi-automated 3D breast ultrasound. Technol Cancer Res Treat 2004; 3: 325-334 